It results in a certain amount of simplification if the region $R_{i}^{\prime}$ is defined as $f_{i} \geqslant A_{1} f_{1}, f_{i} \geqslant A_{2} f_{2}, \ldots$, $f_{i} \geqslant A_{n} f_{k}$, where the $A$ 's are suitably chosen. This, however, differs from the best region obtained above. The comparative advantages of these regions and their use in the statistical theory of choice of one out of many alternatives will be discussed in a paper to be published elsewhere.

I wish to thank Prof. R. A. Fisher for his valuable advice in the preparation of this note.

\section{RadHakrishna RaO}

King's College,

Cambridge.

Aug. 12.

1 Nature, 159, 30 (1947).

- Biometrika, 31, 218 (1939).

\section{Replacement of Fibres in Sheep}

Eмpту follicles, from which the fibres have apparently been shed, have been observed in skin samples from several breeds of sheep of various ages from one month to five years old, namely, Romney, Leicester and Blackface breeds. These skin samples were fixed either in formol saline or in Zenker and stained by a special combination of safranin, alum. carmine and picro-indigocarmine, details of which will be published elsewhere.

Examination of such follicles in horizontal and vertical serial sections has revealed the frequent occurrence of a type of shedding in which the old fibre is lost from the follicle when the new fibre is in the very early stages of its development, so that there is no possibility of the new fibre either growing alongside the old one or mechanically forcing it out, as described in other mammals by Segall ${ }^{1}$ and others. In a few instances, a shed 'club-rooted' fibre was observed lying loosely in the distal part of the follicle some distance above the new fibre cone.

A second interesting feature is the occurrence in the follicle, immediately above the level of the tip of the new fibre cone, of an axis of cells histologically corresponding to the granular layer of the epidermis ; these are apparently 'canal cells' as described in fotal follicles in man by Stöhr' ${ }^{2}$, and also in sheep by Wildman ; but they are placed at a lower level in the follicle in our material than in the foetal material described by Wildman. Segall, on the other hand, denies the presence of 'canal cells' in the guinea pig.

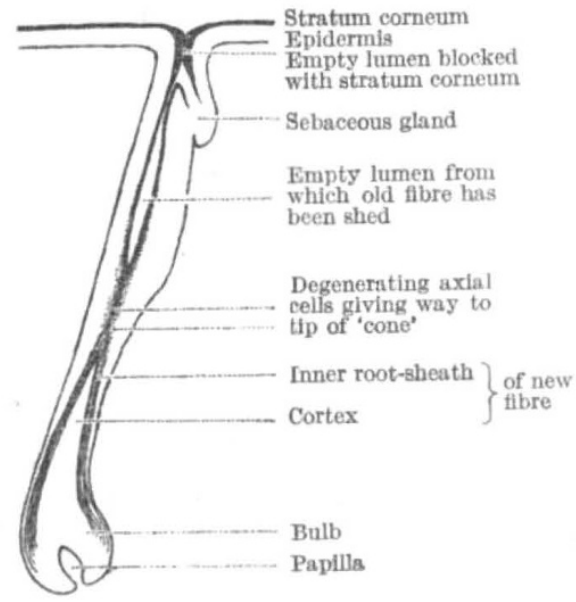

The accompanying diagram illustrates some details of the shedding process just described.

Further work is in progress, in order to determine the frequency and causes of this and other types of fibre-shedding in sheep, and to elucidate the cytological details of shedding and replacement of fibres. Foetal material prepared in the above way will also be examined for the presence of an axis of granular layer cells in the developing follicles.

\section{AUBER}

Marca Burns

Biology Department,

Wool Industries Research Association, Torridon, Headingley, Leeds 6.

Aug. 29.

'Sogall, A., Arch. Mikr. Anat., 91 (1918).

'Stöhr, Ph., Anat. Hefte, 23, 71 (Nov. 1903).

- Wildman, A. B., P.Z.S., Pt. 2 (1932).

\section{New Divisions of Vascular Plants}

A WIDELx used classification of vascular plants has recognized four divisions: Psilopsida, Lycopsida, Sphenopsida and Pteropsida ${ }^{1}$. The first three have been erected in the course of time out of Jeffrey' $\mathrm{s}^{2,3,5,5 \pi}$ original Lycopsida. The fourth has not been changed from Jeffrey's ${ }^{2,4,5,5 \infty}$ original Pteropsida, and is further subdivided into Filicinex (ferns) and Spermatophyta (seed plants)-both very large groups. The three divisions and these two subdivisions make five groups of plants widely recognized as distinct groups, though accorded a variety of taxonomic ranks.

Having to teach over the whole range of botany for some years, I have had problems of taxonomy at the higher levels forced on my attention, and for some time have felt a difficulty in expounding the Pteropsida as a coherent group corresponding to the Psilopsida, Lycopsida and Sphenopsida. Our presentday clearer knowledge of meristematic activity at apices, and in the origin of leaf primordia and branch primordia, together with other considerations, has led me to propose that the division Pteropsida be replaced by two divisions, the Filicopsida (ferns) and Spermatopsida (seed plants).

These two divisions may be differentiated as follows.

Filicopsida (the ferns, formerly Filicineæ-se日 Eames ${ }^{1}$-or Filicales-see Scott $^{6}$ and Bower $\left.{ }^{7}\right):(a)$ One superficial apical cell or 1-4 uniform superficial apical cells as initiators of structure. (b) Primary branching at the apex of the shoot infrequent, prominently dichotomous* and terminal. (c) Leaves arise from one or a very few superficial cells and develop superficial apical cells. (d) Sporangia of only epidermal origin. (e) Dispersed as spores.

Spermatopsida (the seed plants, formerly Spermatophyta-see Rendle ${ }^{8}$ and Eames ${ }^{1}$-or Spermophytasee Scott $^{6}$ ): (a) Differentiated, massive meristem, several layers deep, as initiator of structure. (b) Primary branching at the apex of the shoot frequent, lateral and axillary to the leaves. (c) Leaves arise by combined activity of a zone of cells several layers deep, and develop a meristem which, if apical, is massive and differentiated. (d) Sporangia of essentially hypodermal origin. (e) Dispersed as seeds.

Just $^{9}$ has put forward a timely plea for observance of the Rules of Botanical Nomenclature in connexion with the major groups of plants. There are great difficulties here as the relevant data are much more complex than for the minor groupings-species, 